\title{
Diagnostic Value of Integrated Ultrasonic Backscatter in Congestive Cardiomyopathy
}

\author{
Kemal Baysal, M.D., * Serap Uysal, M.D., ** \\ and Arman Bilgiģ, M.D.***
}

\section{Summary}

Congestive cardiomyopathy is a fatal myocardial disease which can be diagnosed by clinical findings, electrocardiography, roentgenography and echocardiography. Tissue characterization and pathology have been determined recently using histogram methods to analyze ultrasonographs. In this study ultrasonic backscatter analysis for differentiation of normal and diseased myocardium was tested. Two-dimensional echo data and radio frequency signals of long-axis views of the left ventricular posterior wall of 10 healthy children and 14 patients with congestive cardiomyopathy in systolic and diastolic phase were digitized online into the computer memory. Cyclic variation was obtained in the control group but no variation was detectable in myopathic hearts.

\section{Key Words:}

Integrated ultrasonic backscatter Congestive cardiomyopathy

\begin{abstract}
MONGESTIVE cardiomyopathy is characterized by massive cardiomegaly
4 as a result of the extensive dilatation of the ventricles, especially of the left one. Myocardial performance is poor as evidenced by reduced stroke volume, low ejection fraction and increased systolic and diastolic volumes. ${ }^{1)-3}$ ) Many attempts have been made to differentiate tissue characteristics of cardiomyopathic myocardium from that of normal myocardium with ultrasound. Ultrasonic attenuation and backscatter, which have been quantified for the purpose of myocardial tissue characterization, reflect acoustic properties of the tissues. ${ }^{2,3}$ In this study, patients diagnosed as having congestive cardiomyopathy were studied using an M-mode format integrated backscatter imaging system to characterize the range of cyclic variation of integrated backscatter, and were compared with normal subjects.
\end{abstract}

From the Ondokuz Mayis University, School of Medicine, Department of Pediatric Cardiology, Samsun, Turkey.

* Associate Professor, Pediatric Cardiologist.

** Assistant Professor, Pediatrician.

*** Professor, Pediatric Cardiologist.

Mailing address: Scrap Uysal, M.D., P.K. 198, 55000, Samsun, Turkey.

Received for publication November 26, 1990.

Accepted June 3, 1991. 


\section{Subjects and Methods}

A total of 14 patients and 10 healthy children were included in this study. Eight males of 6 months to 4 years of age and 6 females of 1 year to 6 years of age with congestive cardiomyopathy and an age matched control group of 6 males and 4 females were analysed. The etiology of the cardiomyopathy was idiopathic in our patients. General characteristics of the patients are shown in Table I. Two-dimensional M-mode ultrasonography integrated backscatter images were obtained in both the patients and healthy children. M-mode two-dimensional echocardiographic studies were performed using ultrasonography (Toshiba Sonolayer SSA-90A, Tokyo) with a $3.75 \mathrm{MHz}$ transduccr. A certain area on the left ventricle posterior wall was designated.

For each subject a one square $\mathrm{cm}$ area on the left ventricular posterior wall was measured in pixels and measurements of the ultrasonograph were made accordingly by the computer. The histogram indicated the gradation characteristics of the area specified on an image obtained by the ultrasound diagnostic system in quantitative form. Histogram display:

1. Horizontal axis: Gradation (64 grades, 0-63).

Table I. Clinical Characteristics of the Patients

\begin{tabular}{|c|c|c|}
\hline \multirow{2}{*}{ Sex } & Male & $8(57.1 \%)$ \\
\hline & Fenale & $6(42.9 \%)$ \\
\hline \multicolumn{2}{|c|}{ Age (range) } & 6 months -6 years (mean: 4 years) \\
\hline \multicolumn{2}{|c|}{ Duration of symptoms (range) } & 1 month -4 years (mean: 18 months) \\
\hline \multicolumn{2}{|c|}{ Follow-up period (range) } & 2 months -4 years (mean : 2.5 years) \\
\hline \multirow{2}{*}{ Outcome } & Alive & $8(57.1 \%)$ \\
\hline & Exitus & $6(42.9 \%)$ \\
\hline
\end{tabular}

Table II. Calculation Formula

\begin{tabular}{|c|c|c|}
\hline Maximum frequency $(\%)$ & MAX & $\frac{\text { No. of samples of maximum - frequency grade }}{\text { Total No. of samples }}=\frac{100 \text { pix }}{N(\text { pix })}$ \\
\hline \multirow[t]{2}{*}{ Average gradation } & \multirow[t]{2}{*}{$\mathbf{M}$} & $\sum_{0}^{63}$ (Each gradation $\times$ No. of samples of its grade) \\
\hline & & Total No. of samples \\
\hline Standard deviation & SD & $\sqrt{\frac{\sum \text { (Gradation at each sample point-average gradation) }}{\text { Total No. of samples (TOTAL-No. of pixels) }}}$ \\
\hline Total No. of pixels & $\mathrm{N}$ & Total number of samples \\
\hline
\end{tabular}




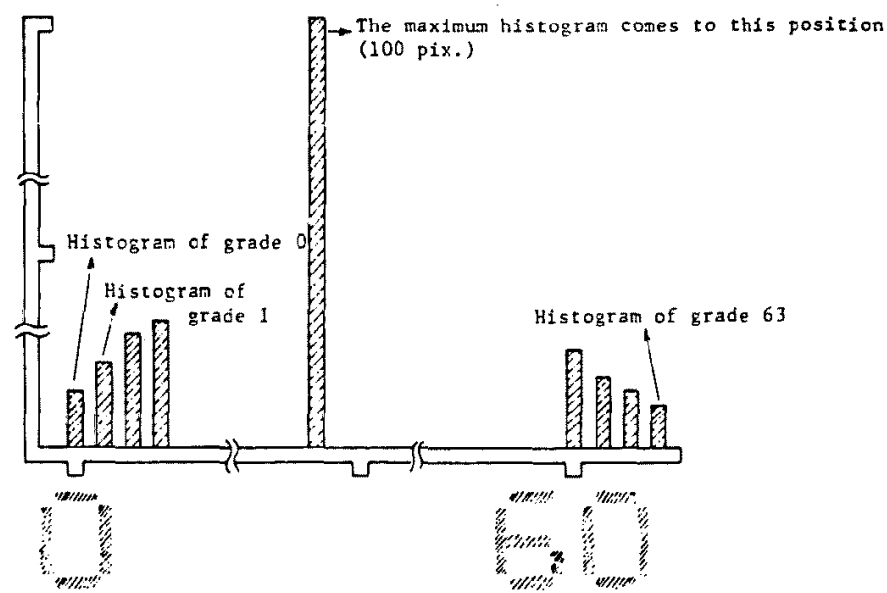

Fig. 1. Histogram display.

(1) Horizontal axis: Gradation (64 grades).

(2) Vertical axis: Frequency.

2. Vertical axis: Frequency.

The maximum frequency was normalized on the display and regarded as the maximum display (100 pixels) on the vertical axis (Fig. 1).4) Calculation values were determined by the analyser in the machine according to the formulas seen in Table II.

Statistical analysis was carried out using Student's t-test.

\section{Results}

The left ventricular posterior wall histogram values of the patients with congestive cardiomyopathy were $36.3 \pm 4.5 \%$ for systole and $36.2 \pm 4.1 \%$ for diastole. No statistically significant difference between these two values was found in the group. Systolic $(33.1 \pm 6.8 \%)$ and diastolic $(26.1 \pm 10 \%)$ values obtained in the control group were statistically different. In Table III, the histogram results of the groups are displayed.

\section{Discussion}

Clinical echocardiography, which is often employed at present, enables the evaluation of M-mode patterns and two-dimensional images of the smooth, large interfaces of the heart such as endocardial and epicardial surfaces. ${ }^{2,5}$ Quantitative evaluation of echoes of lower amplitude, such as those from the myocardium has widely been used clinically. It may be useful in the diagno- 
Table III. Comparison of the Left Ventricle Posterior Wall Histogram Values in Systole and Diastole

\begin{tabular}{l|c|cc}
\hline & $\begin{array}{c}\text { Patients } \\
\mathrm{n}: 14\end{array}$ & $\begin{array}{c}\text { Controls } \\
\mathrm{n}: 10\end{array}$ & \\
\hline Systole & $36.3 \pm 4.5 \%$ & $33.1 \pm 6.8 \%$ & $\mathrm{p}<0.05$ \\
\hline Diastole & $36.2 \pm 4.1 \%$ & $26.1 \pm 10 \%$ & $\mathrm{p}<0.05$ \\
\hline & $\mathrm{p}>0.05$ & $\mathrm{p}<0.05$ &
\end{tabular}

sis of myocardial structure and perfusion and may be accomplished by the analysis of radio frequency data to determine integrated ultrasonic backscatter occurring in response to cardiac contraction on echo image data which would be important to show the abnormalities in myocardial structure. ${ }^{5), 6)}$ Integrated ultrasonic backscatter from normal myocardium has been shown to vary with the phase of cardiac contraction (decreasing from end-diastole to end-systole). ${ }^{31-5)}$ We analysed 24 subjects (14 patients, 10 controls) with echocardiographic imaging, and integrated backscatter was measured with the twodimensional imaging system. The histogram values at the end of systole and diastole were calculated; a significant difference between these two values was not found in the patients with congestive cardiomyopathy.

Two studies of histogram values in congestive cardiomyopathy were found in the literature. 7,8 , In a series of 20 cases, left ventricular posterior wall histogram values for systole and diastole were different, but no statistical difference was found. ${ }^{7)}$ In the other study, whereas a healthy control group showed cyclic variations, there was no cyclic variation in the patients with congestive cardiomyopathy. ${ }^{81}$ We obtained entirely different results in our patients in comparison with the second study. ${ }^{81}$

We demonstrated the disappearance of the difference caused by the decreased transmission of radio frequency waves through the altered myocardium. In conclusion, in cardiomyopathic patients the cyclic variation of the left ventricle histogram values disappear. Therefore, left ventricular posterior wall histogram values may be useful for the diagnosis of myocardial change in congestive cardiomyopathy.

\section{REFERENCES}

1. Maron BJ: Idiopathic congestive cardiomyopathy. in Moss' Heart Disease in Infants, Children and Adolescents, 3rd Ed, ed by Adams FH, Emmanouilides GC, Williams and Wilkins, London, p 774-776, 1984

2. Olshansky B, Collins S, Skorton D, Prasad NV: Variation of left ventricular myocardial gray level on two-dimensional echocardiograms as a result of cardiac contraction. Circulation 70: 
972,1984

3. Rhyne TL, Sager KB, Wann SL, Haasler G: The myocardial signature: absolute backscatter, cyclical variation, frequency variation and statistics. Ultrasonic Imaging 80: 107, 1986

4. Amplitude Histograms. in Application Manual for Electronic Scanning Type Ultrasound Diagnostic Equipment Models SSA-90A No: 2B730-183 E *C, p $46-47$

5. Masuyama T, Nellessen U, Schnittger I, Tye TL, Haskell WL: Ultrasonic tissue characterization with a real time integrated backscatter imaging system in normal and aging human hearts. J Am Coll Cardiol 14: 1702, 1989

6. Hikichi $\mathrm{H}$, Tanaka $\mathrm{M}$ : Ultrasonocardiotomographic evaluation of histological changes in myocardial infarction. Jpn Heart J 22: 287, 1981

7. Vered Z, Barzilai B, Mohr A, Thomas LJ: Quantitative ultrasonic tissue characterization with realtime integrated backscatter imaging in normal human subjects and in patients with dilated cardiomyopathy. Circulation 76: 1067, 1987

8. Angemann CE, Hart RJ, Stempfe U, Zwehl W, Theisen K: Frame by frame quantitation of myocardial backscatter abstracts. Circulation 74 (suppl II): II-271, 1986 